\title{
SELF-REPORTED PREVALENCE OF LOW BACK PAIN IN ESTONIAN ROWERS
}

\author{
Mati Arend, JaAnus Akel, Liısa Haabpiht, Janno Jürgenson \\ Institute of Sport Sciences and Physiotherapy, Faculty of Medicine, \\ University of Tartu, Tartu, Estonia
}

\begin{abstract}
The aim of this study was to determine the lifetime prevalence and point prevalence of low back pain (LBP), the related pain intensity and the rowing-related aggravating factors for LBP in Estonian rowers. A total of 78 rowers ( 38 female and 40 male subjects) completed a single questionnaire at the start of the competitive rowing season to determine lifetime and point prevalence, pain intensity and rowing-related LBP aggravating factors. The lifetime prevalence was high in both male and female rowers (90\% and 93\%, respectively), and the reported point prevalence of LBP was $10 \%$ in males and $21.1 \%$ in females. Female rowers reported significantly higher $(\mathrm{p}=0.02)$ LBP intensity when training 7-16 hours per week, when compared to females whose training volume was less than six hours per week. Rowing-related LBP aggravated factors were long rowing workouts, weight training and sitting for a long period of time. LBP is highly prevalent in rowers and female rowers seemed to be more prone to developing higher intensity LBP when training loads increased. Coaches should cooperate more with sports medicine specialists to better prepare female athletes core endurance to tolerate longer duration rowing workouts and prevent LBP.
\end{abstract}

Keywords: rowing-related aggravating factors for low back pain; Visual Analog Scale

\section{INTRODUCTION}

Low back pain (LBP) is a common complaint in the general and athletic population but athletes seem to be at higher risk of LBP $[3,12,27]$. Not all 
sports are equally prone to LBP and sport specific factors should be taken into consideration and previous research has outlined that wrestlers have the highest probability of developing LBP compared to footballers and tennis players [13]. Bahr et al. [3] compared the prevalence of LBP in cross-country skiing, rowing and orienteering, where different loading patterns on the lumbar region are used. In skiing, athletes mainly load the low back during forward flexion of the hip, while in rowing low back is mainly stressed in backwards extension $[13,23]$. The results showed LBP to be more common among cross-country skiers and rowers than orienteering and a group of non-athletic controls which indicates that cross-country skiing and rowing might be considered as risk factors in development of LBP [3]. Also, in elite junior rowing population there appears to be gender differences in LBP incidences - reported incidence for males were $34.4 \%$ and $29.9 \%$ for females $[24,29]$.

The sport of rowing puts high loads through the lower back during the rowing stroke and low back is the major connection in the transfer of power from the legs to the oar [7]. For example, during a simulated rowing race piece on an ergometer the peak compressive forces in the lumbar spine were $2694 \pm 609 \mathrm{~N}$ and the shear load in lumbar spine averaged $848 \pm 133 \mathrm{~N}$ for the males up to $717 \pm 69 \mathrm{~N}$ for the females [15]. In sports putting high loads or extreme flexibility on the spine, studies have shown higher prevalence of LBP and radiological changes in lumbar spine $[4,9,13,25,28]$.

The injuries affecting rowers are primarily from overuse $[11,24]$ and a review of these injury patterns in the rowing programs at Harvard and Rutgers universities revealed 180 injuries to rowers over a 3-year period and the occurrence corresponds to the periods of intense training in the fall and winter months prior to the racing season [7]. Aggravating factors of LBP from previous research $[5,22,26,29]$ indicate that repeated spinal flexion loading coupled with high training volume and intensity, higher body mass and greater height, training volume on rowing ergometer and increased lumbar flexion during ergometer training were linked with LBP in rowers $[21,30]$. These aggravating factors may vary, since it has been shown that males row with a more slouched posture than females during ergometer rowing [16] and males seem to have poorer relative back muscle endurance than females [14].

Since rowers are shown to be highly influenced by LBP, it is relevant for this subgroup of athletes to understand the aggravating factors of LBP in order to manage and prevent LBP, the purpose of this study was to measure the prevalence and the aggravating factors for LBP in Estonian rowers. 


\section{MATERIALS AND METHODS}

\section{Subjects}

After approaching rowing clubs and coaches via e-mail, 78 rowers who regularly participated in rowing training volunteered to participate in this study (Table 1). From the volunteered subjects, novice rowers (1-2 seasons training) represented $20 \%(\mathrm{n}=15)$ and rowers who had trained $>3$ years represented $80 \%(n=63)$.

Table 1. Mean $( \pm S D)$ characteristics of the athletes.

\begin{tabular}{lcccccc}
\hline & & Age $(\mathbf{y})$ & $\begin{array}{c}\text { Height } \\
(\mathbf{c m})\end{array}$ & $\begin{array}{c}\text { Body } \\
\text { mass }(\mathbf{k g})\end{array}$ & $\begin{array}{c}\text { Years of } \\
\text { rowing }\end{array}$ & $\begin{array}{c}\text { Weekly training } \\
\text { hours }\end{array}$ \\
\hline Males & $\mathrm{n}=40$ & $26.1 \pm 8.8$ & $186.5 \pm 6.6$ & $84.1 \pm 10.6$ & $5.6 \pm 2.3$ & $7.55 \pm 0.9$ \\
\hline Females & $\mathrm{n}=38$ & $22.8 \pm 7.0$ & $173.3 \pm 6.3$ & $69.3 \pm 7.9$ & $4.2 \pm 2.2$ & $8.0 \pm 1.0$ \\
\hline
\end{tabular}

\section{Procedures}

Participants in this study completed a single questionnaire [16] distributed by the researchers via e-mail at the start of the competitive rowing seasons (April - May). The questionnaire was in an online format (Google Forms). Permission to conduct this study was granted by the Research Ethics Committee of University of Tartu (approval number 247T_17).

The questionnaire [16] included questions on general characteristics such as age, height and body mass followed by questions related to prevalence of LBP. Explanations for LBP were given in the questionnaire and it was defined as pain located between L1 and gluteal folds, and this area of the body was pictured in the questionnaire [16]. The Visual Analog Scale (VAS) was used to determine the level of the LBP intensity in the week prior to data collection [17]. Rowers with LBP were then able to select factors from a list that brought on or exacerbated their LBP. This list included the following factors: lifting a rowing shell, rowing in a sweep boat, rowing in a double scull, rowing in a single scull, ergometer rowing or long rows ( $>20 \mathrm{~min}$ of continuous ergometer or on-water rowing) in a training session. They were also given the opportunity to specify other factors that aggravated their LBP. Quadruple scull rowing as an aggravating factor was left out since in Estonia rowers train on smaller boats at the start of their rowing season. The questionnaire concluded by assessing the number of rowing-related training hours (h) and other sporting commitments. 


\section{Statistical analysis}

Statistical analyses were performed using SPSS v21.0 (SPSS, Inc., Chicago, USA). Means and standard deviations were used to present the participants' height, body mass, age and LBP intensity. The Mann-Whitney U and Kruskal-Wallis tests were used to determine whether differences in the intensity of LBP were evident between groups.

\section{RESULTS}

Participants reported high prevalence of LBP and Figure 1 represents the reported values of LBP among male (90\%) and female (93\%) rowers, the point prevalence of LBP in male and female rowers was $10 \%$ and $21 \%$, respectively. There was no statistically significant difference between male and female rowers in the prevalence or the point prevalence of LBP $(\mathrm{p}=0.747$ and $\mathrm{p}=0.179$, respectively).

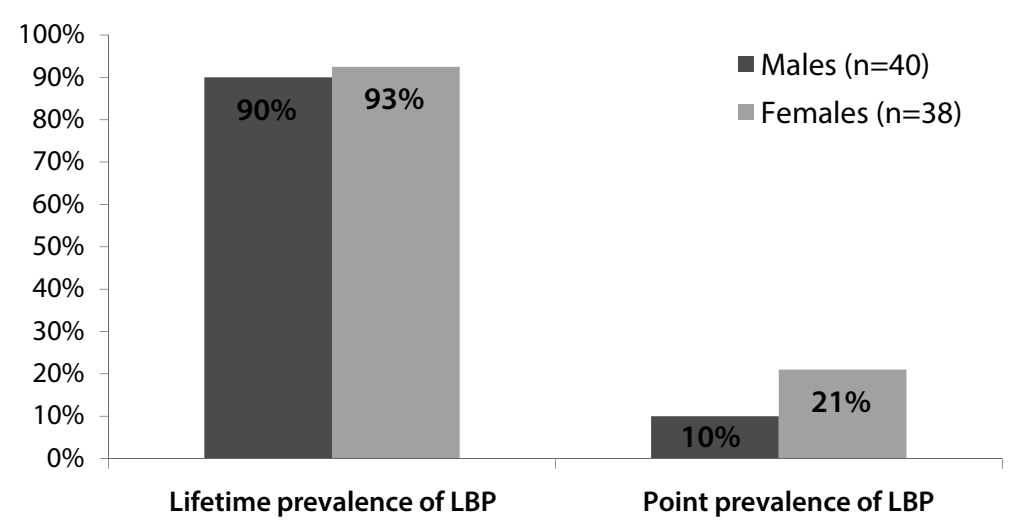

Figure 1. Lifetime and point prevalence of low back pain (LBP) during the week prior to filling in the questionnaire in male and female rowers.

Figure 2 represents the average LBP pain intensity ratings in rowers who reported having LBP in the previous week using the 11-point Visual Analog Scale (VAS) where zero points represents no problem or pain and ten points represents worst possible pain. Pain intensity of the LBP was statistically significantly higher $(\mathrm{p}=0.03)$ in female rowers compared to male rowers $(2.9 \pm 2.4$ and $1.8 \pm 2.1$ points, respectively). 


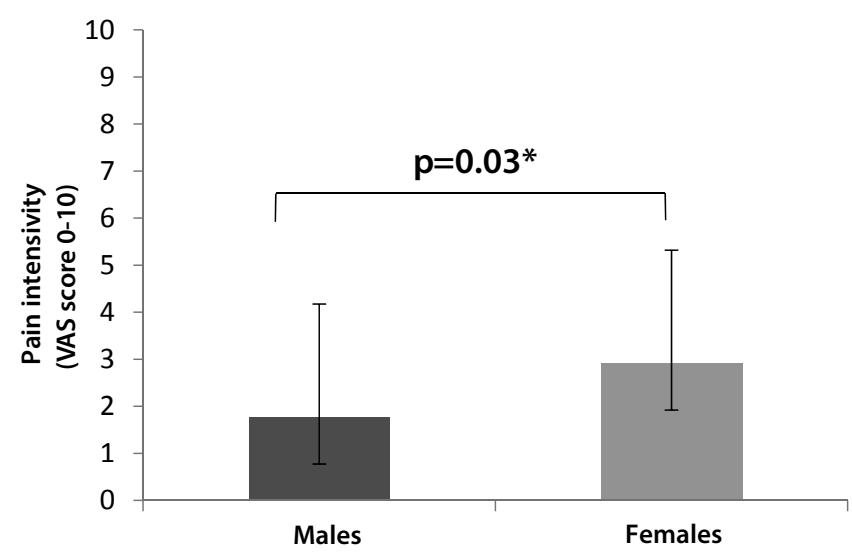

Figure 2. Differences in the intensity of low back pain (LBP) in male and female rowers using subjective numerical pain rating Visual Analog Scale (VAS).

Figure 3 shows the average values of training hours on the water and the average LBP intensity in male and female rowers. In male rowers, there was no statistical difference $(\mathrm{p}=0.84)$ in LBP intensity between those who trained up to six hours per week compared to rowers who trained seven to 16 hours per week. Female subjects who rowed seven to 16 hours per week reported statistically $(\mathrm{p}=0.02)$ higher LBP intensity compared to females who trained less than six hours per week.

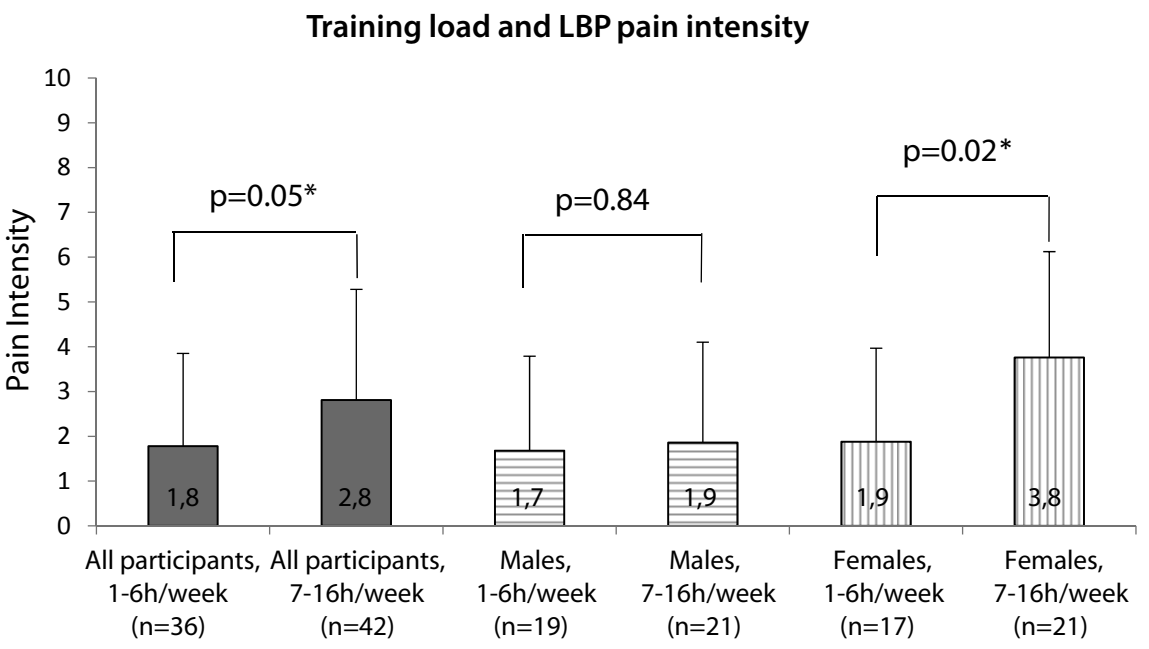

Figure 3. Comparison of rowing related training loads and differences in average low back pain (LBP) intensity between male and female rowers. 
The main aggravating factors for LBP in both female and male rowers are reported in Figure 4. Both male and female rowers reported prolonged sitting and long duration rowing as one of the most aggravating factors which increased their LBP. Compared to male rowers, female rowers reported more frequently weight training to be an aggravating factor for their LBP.

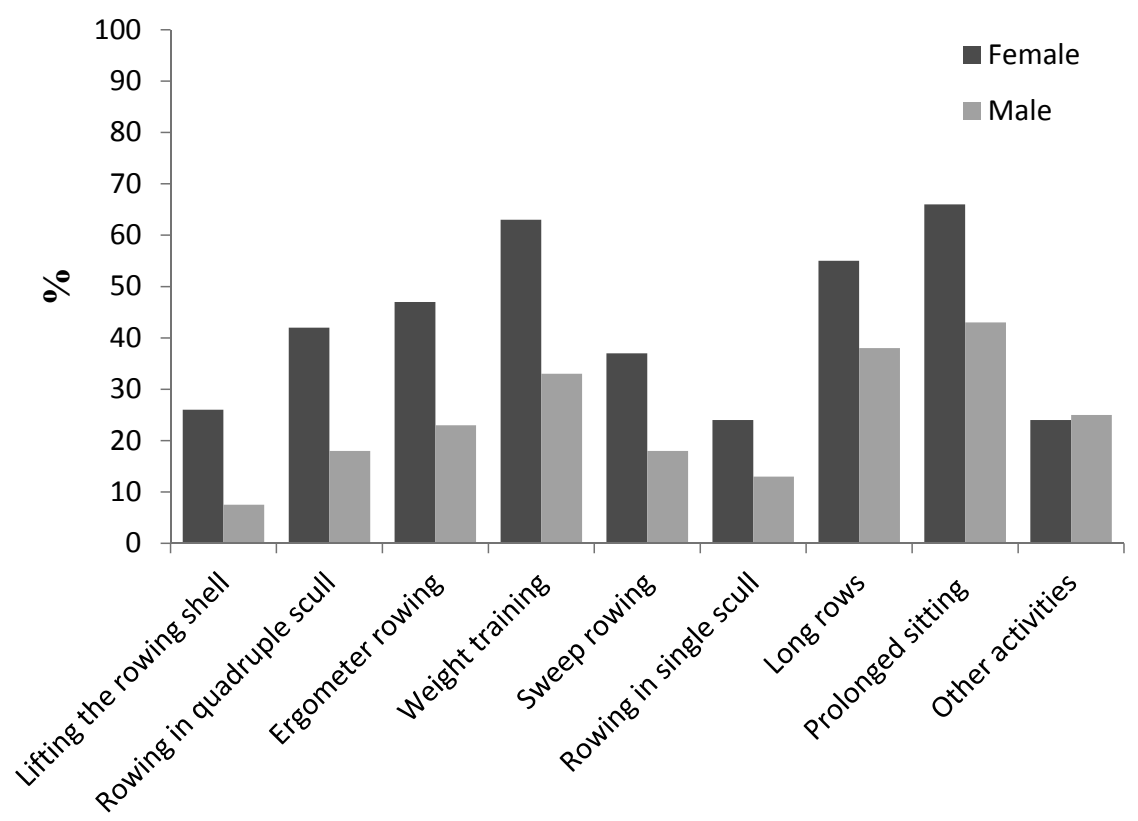

Figure 4. Percentage of self-reported low back pain aggravating factors in male and female rowers.

\section{DISCUSSION}

Low back pain (LBP) is very common in rowing population and the purpose of this study was to measure the prevalence and aggravating factors of LBP in Estonian rowers. The main finding was that rowers in this study reported high lifetime prevalence of LBP (90\% males and 93\% females). Female rowers had significantly higher LBP intensity compared to males, and the main aggravating factors for LBP were higher training loads, long periods of sitting and long duration of rowing trainings.

Previous research [16] on Australian adolescent rowers reported that LBP prevalence was higher in males compared to females $(93.8 \%$ and $77.9 \%$, respectively) and the point prevalences of LBP were $64.6 \%$ and $52.8 \%$. In 
comparison, both male and female rowers reported high prevalence of LBP (90\% and 93\%, respectively). The point prevalence of LBP in the present study was $10 \%$ in male and $21.1 \%$ in female rowers, which in comparison was lower from what $\mathrm{Ng}$ et al. [16] reported in Australian male and female adolescent rowers where LBP point prevalence was $64.6 \%$ and $52.8 \%$, respectively. Similarly, previous studies in elite junior rowing population showed gender differences in LBP incidences - 34.4\% in males and 29.9\% in females $[24,29]$. Both in our study and in $\mathrm{Ng}$ et al. [16] study the questionnaire was delivered to the rowers at the start of their competitive season and the differences in the point prevalence of LBP might be from participant's age differences. The higher point prevalence of LBP in female rowers might be from increased training load [29] since female rowers in our study trained longer on the water and on the rowing ergometer compared to male rowers.

Previous research has pointed out that longer duration training is a factor that affects LBP $[16,26,29]$. In our study, the results showed that female rowers who trained more than seven hours per week reported significantly $(\mathrm{p}=0.02)$ higher LBP intensity compared to females who trained less than six hours per week. The average intensity of LBP was higher by 1.9 on VAS, which is in accordance to the previous research data indicating that an average difference of 1.3 on a VAS represents the minimum clinically significant change in pain intensity [8]. The repeated low back flexion and extension movements in rowing might cause overuse and injuries in the area of lower back $[1,2,7,22]$. Therefore, rowing coaches should better prepare rowers (especially female rowers) core endurance training before starting the longer duration trainings on the water or on the rowing ergometer to prevent LBP.

Previous studies have pointed out that reduced back muscle endurance and sitting posture were associated with LBP in schoolgirl rowers [20]. Harringe et al. [6] evaluated specific segmental muscle control exercises in young female gymnasts and demonstrated their effectiveness in reducing LBP, although the exercises were not athlete specific. In our study, female rowers reported more aggravating factors for LBP compared to male rowers male subjects reported a total of 86 aggravating factors compared to females who reported a total of 146 LBP aggravating factors. The main aggravating factor for LBP in both male and female rowers was long period of sitting (reported by $66 \%$ females and $43 \%$ males), followed by weight training in females (63\%) and long rowing in males (38\%). Additionally, almost half of the female rowers reported ergometer rowing and rowing in a double scull as an aggravating factor for their LBP (Figure 4), which is similar to 
previous research indicating that training volume on rowing ergometer and increased lumbar flexion during ergometer training are linked with LBP $[21,30]$. Also, during weight lifting an improper spinal mechanics that is performed hundreds of times in one training session might be one of the common factors in predisposing young athletes to low back dysfunction [10]. The fact that many rowers from both groups reported weight training as an aggravating factor for LBP, makes it very important that coaches and athletes know and teach the proper lifting techniques before starting to lift heavier weights that have higher potential for an injury.

Chronic LBP is a complex combination of physical, psychological, lifestyle, cognitive, social and neuro-physiological factors [18]. In our study, LBP had a negative effect on athletes' trainings $-53.8 \%$ of the rowers reported having substituted or cancelled their rowing trainings due to LBP. Unfortunately, only $56 \%$ of the subject in the present study had sought out medical help for their LBP. From this it can be concluded that rowers tend to wait and see and hope that LBP will pass while regularly training through pain might lead to development of chronic issues. This makes the preventive work on LBP even more important and as Perich et al. [19] described the best way to decrease the incidences of LBP is by using multi-dimensional programme which involves athlete education, individualised "specific" exercise intervention from pre-season musculoskeletal screening, combined with off-water strength and conditioning training.

Limitations in this study are the subjective form of questionnaire and the fact that we did not follow up with an interview to specify the extent and nature of the problem. Retrospective questions in the questionnaire might not give the most accurate answers as well as Visual Analog Scale usage in deciding the subjective pain intensity.

In conclusion, a high lifetime of LBP (90\% in males and $93 \%$ in females) yet low point-prevalence of LBP ( $10 \%$ in males and $21 \%$ in females) were reported by Estonian rowers at the start of their competitive season. Biggest LBP aggravating factors were long periods of sitting and long duration rowing training. Rowers and coaches need to be more educated what LBP is, what are the risk factors and how to prevent it [31]. Female rowers reported significantly higher intensity of LBP when the training load was higher (7-16 h/ week). 


\section{REFERENCES}

1. Adams M, McNally D, Chinn H, Dolan P. (1994) Posture and the compressive strength of the lumbar spine. Clin Biomech, 9: 5-14

2. Adams M, Dolan P. (1995) Recent advances in lumbar spinal mechanics and their clinical significance. Clin Biomech, 10: 3-19

3. Bahr R, Andersen S, Løken S, Fossan B, Hansen T, Holme I. (2004) Low back pain among endurance athletes with and without specific back loading - a cross-sectional survey of cross-country skiers, rowers, orienteerers, and nonathletic controls. Spine, 29(4): 449-454

4. Bennett DL, Nassar L, DeLano MC. (2006) Lumbar spine MRI in the elite-level female gymnast with low back pain. Skeletal Radiol, 35: 503-9

5. Caldwell JS, McNair PJ, Williams M. (2003) The effects of repetitive motion on lumbar flexion and erector spinae muscle activity in rowers. Clin Biomech, 18: 704-711

6. Harringe M, Nordgren JS, Arvidsson I, Werner S. (2007) Low back pain in young female gymnasts and the effect of specific segmental muscle control exercises of the lumbar spine: a prospective controlled intervention study. Knee Surg Sports Traum Arthosc, 15: 1264-1271

7. Hosea TM, Hannafin JA. (2012) Rowing injuries. Sports Health, 4(3): 236-45

8. Gallagher EJ, Liebman M, Bijur PE. (2001) Prospective validation of clinically important changes in pain severity measured on a visual analog scale. Ann Emerg Med. 38: 633-638

9. Granhed H, Morelli B. (1988) Low back pain among retired wrestlers and heavyweight lifters. Am.J.Sports Med, 16: 530-3

10. Geraci MC, Brown W, Velasquez JR. (2005) Low back pain in adolescent athletes: Diagnosis, Rehabilitation, and Prevention. Human Kinetics ATT, 10(5): 6-16

11. Karlson KA. (2000) Rowing injuries: identifying and treating musculoskeletal and non musculoskeletal conditions. Phys Sports Med, 28(4): 40

12. Kujala UM, Kinnunen J, Helenius P. (1999) Prolonged low-back pain in young athletes: a prospective case series study of findings and prognosis. Eur Spine J, 8: $480-484$

13. Lundin O, Hellstrom M., Nilsson I. (2001) Back pain and radiological changes in the thoraco-lumbar spine of athletes. A long-term follow-up. Scand J Med Sci Sports, 11: 103-109

14. Mannion AF, Dumas GA, Cooper RG, Espinosa FJ, Faris MW, Stevenson JM. (1997) Muscle fibre size and type distribution in thoracic and lumbar regions of erector spinae in healthy subjects without low back pain: normal values and sex differences. J Anat, 190: 505-513

15. Morris FL, Smith RM. (2000) Compressive and shear force generated in the lumbar spine of female rowers. Int J Sports Med, 21(7): 518-523 
16. Ng L, Perich D, Burnett A, Campbell A, O’Sullivan P. (2014) Self-reported prevalence, pain intensity and risk factors of low back pain in adolescent rowers. J Sci Med Sport, 17(3): 266-270

17. Ogon M, Krismer M, Sollner W, Kantner-Rumplmair, Lampe A. (1996) Chronic low back pain measurement with visual analogue scales in different settings. Pain, 64: 425-428

18. O’Keeffe M, O’Sullivan P, Dankaerts W, O’Sullivan K. (2015) Swiss ball enhances lumbar multifidus activity in chronic low back pain: A letter to the editor. Phys Ther Sport, 16(2):202-3

19. Perich D, Burnett A, O’Sullivan P, Perkin C. (2011) Low back pain in adolescent female rowers: a multi-dimensional intervention study. Knee Surg Sports Traumatol Arthrosc, 19(1): 20-9.

20. Perich D, Burnett A, O'Sullivan P (2006) Low back pain and the factors associated with it: Examination of adolescent female rowers. In: XXVIth symposium on biomechanics in sports, University of Salzburg, Salzburg, 355-358

21. Pollock CL, Jones IC, Jenkyn TR, Ivanova TD, Garland SJ. (2012) Changes in kinematics and trunk electromyography during a $2000 \mathrm{~m}$ race simulation in elite female rowers. Scand J Med Sci Sports, 22: 478-487

22. Reid D, McNair P. (2000) Factors contributing to low back pain in rowers. Brit. J. Sports Med, 34: 321-325

23. Rumball JS, Lebrun CM, Di Ciacca SR, Orlando K. (2005) Rowing injuries. Sports Med, 35: 537-55

24. Smoljanovic T, Bojanic I, Hannafin JA, Hren D, Delimar D, Pecina M. (2009) Traumatic and overuse injuries among international elite junior rowers. Am J Sports Med, 37: 1193-1199

25. Sward L, Hellstrom M, Jacobsson B, Pëterson L. (1990) Back pain and radiologic changes in the thoracolumbar spine of athletes. Spine (Phila Pa 1976.), 15: 124-129

26. Teitz CC, O'Kane J, Lind B. (2002) Back pain in intercollegiate rowers. Am J SportsMed, 30: 674-679

27. Trainor TJ, Trainor MA. (2004) Etiology of low back pain in athletes. Curr Sports Med Rep, 3: 41-46

28. Videman T, Sarna S, Battie MC, Koskinen S, Gill K, Paananen H, Gibbons L. (1995) The long-term effects of physical loading and exercise lifestyles on backrelated symptoms, disability, and spinal pathology among men. Spine (Phila $\mathrm{Pa}$ 1976), 20: 699-709

29. Wilson F, Gissane C, Gormley J. (2010) A 12-month prospective cohort study of injury in international rowers. Br J Sports Med, 44: 207-214

30. Wilson F, Gissane C, Gormley J, Simms C. (2013) Sagittal plane motion of the lumbar spine during ergometer and single scull rowing. Sports Biomech, 12: $132-142$ 
31. Wilson F, Gissane C, McGregor A. (2014) Ergometer training volume and previous injury predict back pain in rowing; strategies for injury prevention and rehabilitation. Br J Sports Med, 48(21): 1534-1537

\title{
Correspondence to:
}

\author{
Mati Arend \\ Institute of Sport Sciences and Physiotherapy \\ Faculty of Medicine \\ University of Tartu \\ Ravila 14a, 50411 Tartu \\ E-mail: mati.arend@ut.ee \\ Phone: (+372) 7375364
}

